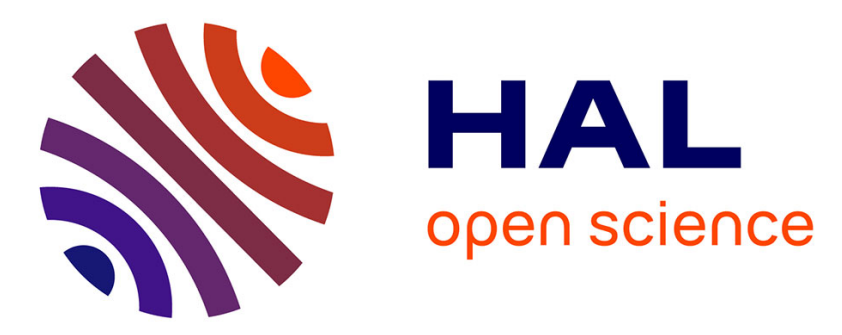

\title{
Effects of surface oxidation on the crystallization characteristics of Ge-rich Ge-Sb-Te alloys thin films
}

Marta Agati, Clément Gay, Daniel Benoit, Alain Claverie

\section{To cite this version:}

Marta Agati, Clément Gay, Daniel Benoit, Alain Claverie. Effects of surface oxidation on the crystallization characteristics of Ge-rich Ge-Sb-Te alloys thin films. Applied Surface Science, 2020, 518, pp.146227. 10.1016/j.apsusc.2020.146227 . hal-03015408

\author{
HAL Id: hal-03015408 \\ https://hal.science/hal-03015408
}

Submitted on 4 Dec 2020

HAL is a multi-disciplinary open access archive for the deposit and dissemination of scientific research documents, whether they are published or not. The documents may come from teaching and research institutions in France or abroad, or from public or private research centers.
L'archive ouverte pluridisciplinaire HAL, est destinée au dépôt et à la diffusion de documents scientifiques de niveau recherche, publiés ou non, émanant des établissements d'enseignement et de recherche français ou étrangers, des laboratoires publics ou privés. 
Effects of surface oxidation on the crystallization characteristics of Ge-rich GeSb-Te alloys thin films

Marta Agati, ${ }^{1, *}$ Clément Gay, ${ }^{1}$ Daniel Benoit, ${ }^{2}$ Alain Claverie. ${ }^{1}$

${ }^{1}$ CEMES-CNRS, 29 Rue Jeanne Marvig, 31055 Toulouse, France.

${ }^{2}$ STMicroelectronics, 850 Rue Jean Monnet, 38926 Crolles, France.

Address the correspondence to Marta Agati at marta.agati@gmail.com

Key-words: Phase Change Materials, Ge-Sb-Te, oxidation, crystallization, surface engineering, transmission electron microscopy. 


\begin{abstract}
We have studied the effect of surface oxidation on the crystallization of Ge-rich GeSb-Te materials, promising for Phase Change Memories working at high temperatures $\left(>350^{\circ} \mathrm{C}\right)$. For this, we have compared the structural and chemical characteristics of films left exposed to air with those shown by TiN-encapsulated films. The effect of air exposure is to lower the temperature at which the onset of crystallization starts by $50-60^{\circ} \mathrm{C}$. Instead of homogeneous nucleation observed in encapsulated films, crystallization proceeds from the surface towards the bulk of the film and results in a massive redistribution of the chemical elements, forming Ge grains which grow until Ge concentration is low enough to allow the $\mathrm{Ge}_{2} \mathrm{Sb}_{2} \mathrm{Te}_{5}$ cubic phase to nucleate. In the air-exposed films, Ge crystallization preferentially occurs at the film surface while the $\mathrm{Ge}_{2} \mathrm{Sb}_{2} \mathrm{Te}_{5}$ grains develop later, at higher temperature, and deeper in the film. Our results strongly suggest that "seeds" are formed in or below the oxide during the early stage of annealing, promoting the heterogeneous nucleation of the Ge cubic phase at a lower temperature than observed in encapsulated films. These seeds necessarily involve oxygen and we speculate that crystalline $\mathrm{Sb}_{2} \mathrm{O}_{3}$ nuclei formed in the surface layer during annealing play this role.
\end{abstract}




\section{Introduction}

After their successful exploitation as storage media for DVDs, Phase Change Materials (PCMs) are again attracting the interest of microelectronic industries as they are foreseen to be used for the next generation of electronic memories, beyond the technological nodes accessible to Flash devices [1-4]. Recently, they have been also explored in the framework of neuromorphic computing and machine learning as synaptic elements in artificial neural networks thanks to the feasibility of multilevel data storage [5-7]. Furthermore, the potential of PCM Random Access Memories to store and process huge amount of data opens the route towards the development of the concept of the Internet of Things [5-7].

PCMs can reversibly transit from the amorphous to the crystalline phases by means of heating processes [2]. Most of the physical properties of these materials are very different, depending on the phase. The large change of optical reflectivity is exploited in optical storage devices. In Phase Change Random Access Memories (PCRAMs), the information bits 0/1 are stored in the high/low electrical resistivity of the respective amorphous and crystalline states. Phase switching is induced by means of electrical power pulses of adequate shapes through Joule heating [1]. Prototypical PCMs are GeTe and $\mathrm{Ge}_{2} \mathrm{Sb}_{2} \mathrm{Te}_{5}$ [8], which have been extensively studied for their rapid switching speed (time scale up to nanosecond [9] and subnanosecond [10]) and high resistivity contrast between the amorphous and crystalline phases (up to $10^{4} \mathrm{ohm} \cdot \mathrm{cm}$ change $[11,12]$ ), thus representing suitable candidates for PCRAMs. The most appealing characteristics of PCRAMs are their cyclability [13], their endurance and fast programming [14], while presenting an extremely easy scaling path [4]. Another important characteristic of a PCM is its crystallization temperature $(\mathrm{T} \chi)$, which dictates the stability of the RESET state and the reliability of the PCRAM when exposed to high working temperatures $[15,16]$. In this respect, the canonical and largely studied $\mathrm{GeTe}$ and $\mathrm{Ge}_{2} \mathrm{Sb}_{2} \mathrm{Te}_{5}$ 
phases show their limit with crystallization temperatures of approximately 230 and $170^{\circ} \mathrm{C}$, respectively.

The quest for PCMs showing high $\mathrm{T} \chi$ (typically larger than $300^{\circ} \mathrm{C}$ ), as desired for specific embedded applications, has triggered the "discovery" of Ge-rich Ge-Sb-Te (GST) alloys, where $\mathrm{T} \chi$ is found to increase with Ge content $[17,18]$. The addition of impurity elements, such as nitrogen [19,20], carbon [21], oxygen[22], bismuth [23] and Sb [24], has also been reported to increase $\mathrm{T} \chi$. Today, $\mathrm{N}$ doped Ge-rich GST alloys appear to be one of the PCMs of choice for such applications [18, 25-27].

However, canonical PCM materials show degraded properties and reduced $\mathrm{T} \chi$ when the films are left exposed for some time to air $[8,11,28,29]$, what may cause serious issues for the manufacturing of devices. If the composition of the "natural" oxide layers which form at the surface of these materials has been studied in detail $[29,30]$, it is only recently that the mechanisms at the origin of this reduced $\mathrm{T} \chi$ have been elucidated, guided by convincing TEM observations $[8,11,12]$. When GeTe is exposed to air, Ge gets selectively oxidized at the surface while Te segregates below this surface. Following this redistribution, Te may crystallize below the oxide layer, at a much lower temperature than $\mathrm{GeTe}\left(180^{\circ} \mathrm{C}\right.$ instead of $230^{\circ} \mathrm{C}$ ), and provide seeds for the subsequent heterogeneous nucleation of the remaining

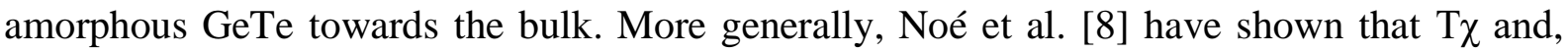
beyond the value, the crystallization mechanisms which are activated at this temperature, depend on the capping or encapsulating layer, mainly through the possible reaction of the film surface with oxygen and on the resulting elemental redistribution which will follow this reaction $[11,12,31]$. In $\mathrm{Ge}_{2} \mathrm{Sb}_{2} \mathrm{Te}_{5}$ films, $\mathrm{Sb}$ can also get oxidized and Te is repelled below the oxide layer [30]. While not as clearly demonstrated, it is reasonable to think that, also in this case, the origin of the lowering of $\mathrm{T} \chi$ observed after air exposure relies on the elemental redistribution, resulting from selective oxidation, and on the formation of Te-rich regions 
which are able to crystallize at low temperature [32] and provide seeds for the subsequent heterogeneous crystallization of GST phases. Interestingly, the evidence of a two-step crystallization process, developing from the surface and propagating towards the depth of the films with different kinetics and length scales, imposes a different reading of previous reports on the influence of the film thickness on the crystallization temperature of GST films, notably when not properly capped [33-35].

Studying the impact of surface oxidation and of the aging of the film left under air exposure, in films of $\sim 100 \mathrm{~nm}$, is a preliminary step in order to disentangle natural oxidation, interface and size reduction effects while planning the scaling down to sub-10 $\mathrm{nm}$ of confined memory cells. While an extensive literature is available about these subjects for GeTe and $\mathrm{Ge}_{2} \mathrm{Sb}_{2} \mathrm{Te}_{5}[8,11,12]$, there is no such analogous report for the newly emerging PCMs based on Ge-rich GST alloys.

In this paper, we report on the effect of air exposure on the crystallization characteristics, onset temperature and mechanisms, of highly Ge-enriched and N-doped GST films. To this purpose, we compare the structural and chemical characteristics of $100 \mathrm{~nm}$ thick films, non-encapsulated and encapsulated by a TiN layer, submitted to annealing at various temperatures and times. Ex-situ characterizations, structural and chemical, of the films after annealing were performed by X-Ray Diffraction (XRD) and Transmission Electron Microscopy (TEM) based techniques. We first show that the observed crystallization temperature is much lower, about $50-60^{\circ} \mathrm{C}$ less, in the films left exposed to air than in those encapsulated. The observation in real time of the crystallization of the films during in-situ annealing in the TEM has been decisive in assessing the different mechanisms by which the full crystallization of the films is obtained. We show that the films left exposed to air suffer some immediate oxidation at their surface and that this oxide layer hosts the seeds which allow the heterogeneous nucleation of the first $\mathrm{Ge}$ crystals at the film surface during 
annealing. This heterogeneous crystallization from the surface, in contrast to the homogeneous crystallization observed in encapsulated films, is accompanied by a massive redistribution of the chemical elements in the depth of the films.

\section{Material and methods}

$100 \mathrm{~nm}$-thick N-doped highly Ge-enriched (E-GST, with $[\mathrm{Ge}]>30 \%$ ) films were deposited on naturally oxidized Si (100) wafers by physical vapor deposition in an industrial cluster tool. These E-GST films were either encapsulated by a $20 \mathrm{~nm}$-thick TiN capping layer or left uncapped in the atmosphere for several months. To encapsulate the E-GST layer, an ultra-thin $(\sim 14 \AA)$ Ti-rich layer was deposited on its surface prior to TiN deposition to favor its adhesion. Samples were annealed in a horizontal Carbolite furnace under atmospheric pressure and $\mathrm{N}_{2}$ flux for durations from 10 minutes up to 16 hours in the $300-450^{\circ} \mathrm{C}$ range. XRD and TEM analyses were performed in parallel on TiN-encapsulated and nonencapsulated E-GST samples. XRD measurements have been carried out using a Bruker D8 Discover diffractometer exploiting a $\mu$ S-Co source $(\lambda=1.789 \AA)$ and a $2 \mathrm{D}$ Vantec 500 detector, in grazing angle configuration at $0.75^{\circ}$. TEM samples were prepared in cross-section by means of either Focused Ion Beam (FIB) or mechanical polishing followed by ion milling techniques. FIB sample preparation was performed using a FEI Helios Nanolab 600 dualbeam FIB and SEM. In all the cases, particular care was taken to limit heating and ballistic effects of ion irradiation of the E-GST film during the final ion milling steps. In-situ annealing experiments in the TEM were carried out using a spherical aberration corrected FEI TECNAIF20 equipped with a FEG source and operating at $100 \mathrm{keV}$ to limit beam effects on the crystallization process [28]. A Philips CM20-FEG TEM working at $200 \mathrm{keV}$ and equipped with a Microanalyser QUANTAX XFlash detector with a $30 \mathrm{~mm}^{2}$ active area and an energy resolution of $127 \mathrm{eV}$ was used for Scanning TEM-Energy Dispersive X-ray spectroscopy 
(STEM-EDX) analyses. Conventional TEM imaging and diffraction experiments on the samples annealed ex-situ were carried out using both CM20-FEG and TECNAI (set at 200 $\mathrm{keV})$.

\section{Results}

\subsection{Physico-chemical characteristics of as-deposited layers}

Figure 1 shows the Bright Field (BF) TEM images of the as-deposited E-GST films. As seen in the images, both films have approximately the same thickness $(95-99 \mathrm{~nm})$, look homogeneous in density and are structurally amorphous, as evidenced by the associated diffraction patterns inserted in the images. At the interface between the Si substrate and the film, the native $\mathrm{Si}$ oxide layer is detected in both samples. In the image of the nonencapsulated E-GST sample, a very thin $(2-3 \mathrm{~nm})$ amorphous oxide layer is visible at the film surface (Figure 1(a)). Alternatively, the polycrystalline TiN layer deposited on the E-GST film is visible in the image of the encapsulated E-GST sample and detected in the associated diffraction pattern (Figure 1(b)). 

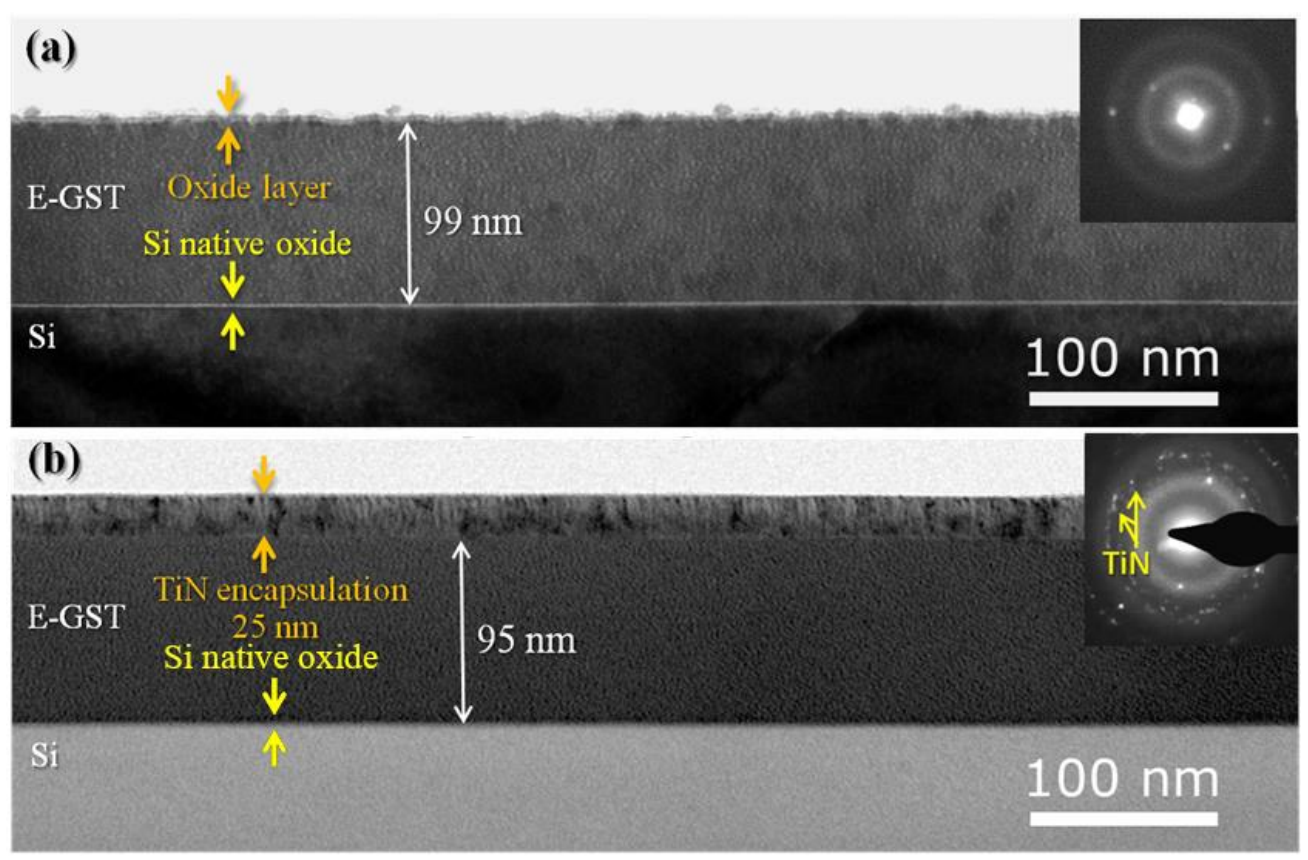

Figure 1. BF TEM images of the as-deposited amorphous E-GST films: (a), non-encapsulated E-GST and (b), TiN-encapsulated E-GST. The associated diffraction patterns are shown in the respective insets.

Figure 2 compares the chemical compositions of these two films. The depthdistributions of the different chemical elements across the films (from the Si substrate up to the sample surface) confirm that the films are homogeneous in composition along their thickness. The native oxide layers between the $\mathrm{Si}$ wafer and the GST films are clearly resolved. However, some differences can be observed. In the encapsulated sample, the interface between the E-GST film and the TiN layer is sharp, as evidenced by the abruptness of the $\mathrm{Ge}, \mathrm{Te}$ an $\mathrm{Sb}$ profiles and their crossing at mid-height with the $\mathrm{Ti}$ and $\mathrm{N}$ profiles. In contrast, in the non-encapsulated sample, the Ge gradient close to the film surface is somehow weaker while the signal from oxygen dramatically increases. This oxygen signal is of about the same width but of sensibly larger amplitude than the one arising from the Si native oxide layer at the E-GST/Si substrate interface. Close inspection of all the profiles shows that not only the Ge content is reduced in the surface region but also the Te and $\mathrm{Sb}$ contents are 
reduced, while oxygen has diffused in the layer, largely over a distance of a few nanometers and slightly over a 30-40 $\mathrm{nm}$ distance.

Finally, these analyses in conjunction with the TEM images shown in Figure 1 tend to indicate that, while the composition of the E-GST film is totally homogeneous in the capped layer, this composition is strongly disturbed in the surface region of the samples by the long air exposure. The surface is covered by some germanium-rich oxide layer of a few nanometers thick, but chemical heterogeneities and oxygen diffusion inside the film are detected over a distance of about $30 \mathrm{~nm}$ from the film surface.
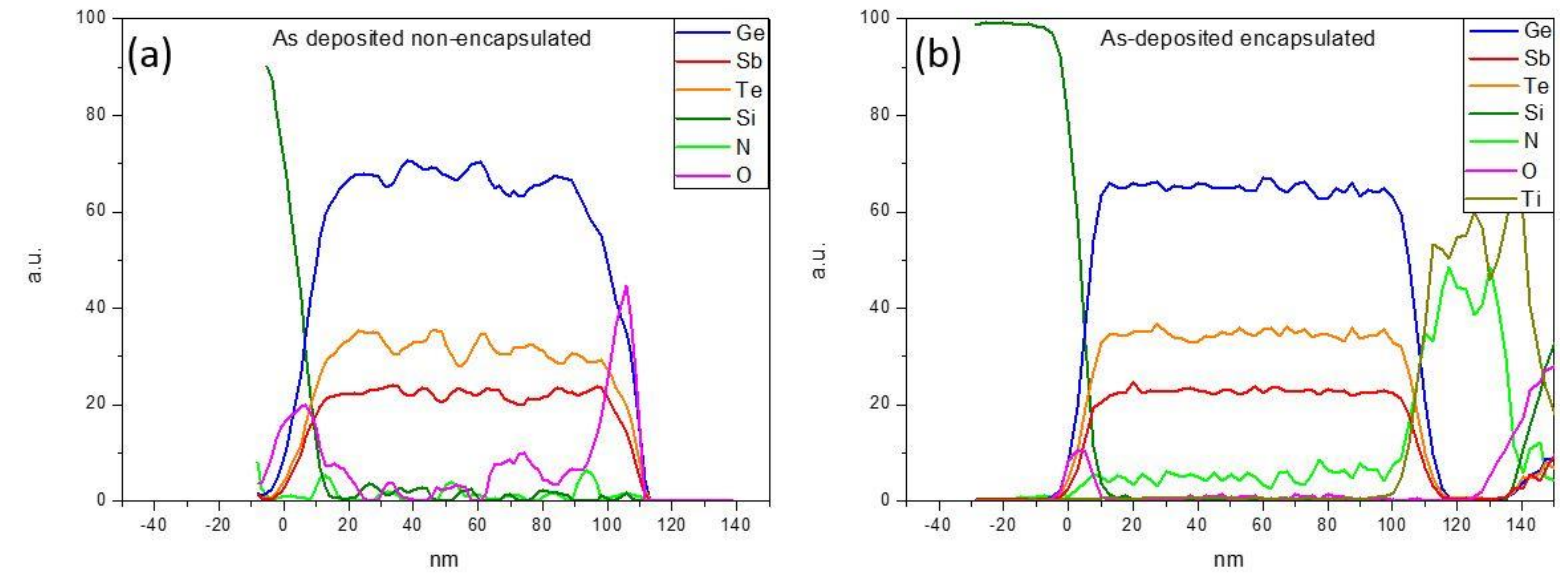

Figure 2. Depth-distributions of the different chemical elements in the as-deposited E-GST films: (a) non-encapsulated and (b) encapsulated. Integration of STEM-EDX images along the depth.

\subsection{Crystallization temperature}

Figures 3(a) and (b) show some of the XRD profiles we have obtained on the encapsulated and non-encapsulated E-GST samples, respectively, after annealing. As previously discussed [36, 37], Figure 3(a) evidences the main characteristics of the crystallization behavior of "air-protected" encapsulated E-GST films. For annealing temperatures lower than $380^{\circ} \mathrm{C}$, the material keeps the same structural characteristics than when deposited, i.e. it is amorphous. Only after annealing at $400^{\circ} \mathrm{C}$ for 10 minutes, diffraction 
peaks start to form and indicate the preferential crystallization of Ge, as shown in [36]. Phase separation between cubic $\mathrm{Ge}$ and $\mathrm{fcc}-\mathrm{Ge}_{2} \mathrm{Sb}_{2} \mathrm{Te}_{5}$ is observed after $450^{\circ} \mathrm{C}, 30$ minutes annealing while a polycrystalline multiphase layer is obtained after $500^{\circ} \mathrm{C}, 30$ minutes annealing. Figure 3(b) shows some of the XRD profiles we have obtained on the nonencapsulated samples, for comparison. To start with, we compare the situation after $380^{\circ} \mathrm{C}, 10$ minutes annealing. While such an annealing has no impact on the structure of the encapsulated film, the non-encapsulated film already shows distinctly the peaks of both the cubic Ge and GST phases. Full crystallization of this layer is obtained after 30 minutes at $450^{\circ} \mathrm{C}$ range. Moreover, one can note that the XRD profile obtained on the air-exposed sample annealed at $330^{\circ} \mathrm{C}$ for 16 hours is about the same than the one obtained on the encapsulated sample annealed at $400^{\circ} \mathrm{C}$ for 30 minutes, indicating that in air-exposed films the crystallization onset initiates at $330^{\circ} \mathrm{C}$, while the same phenomenon is observed at higher temperatures in the encapsulated film.
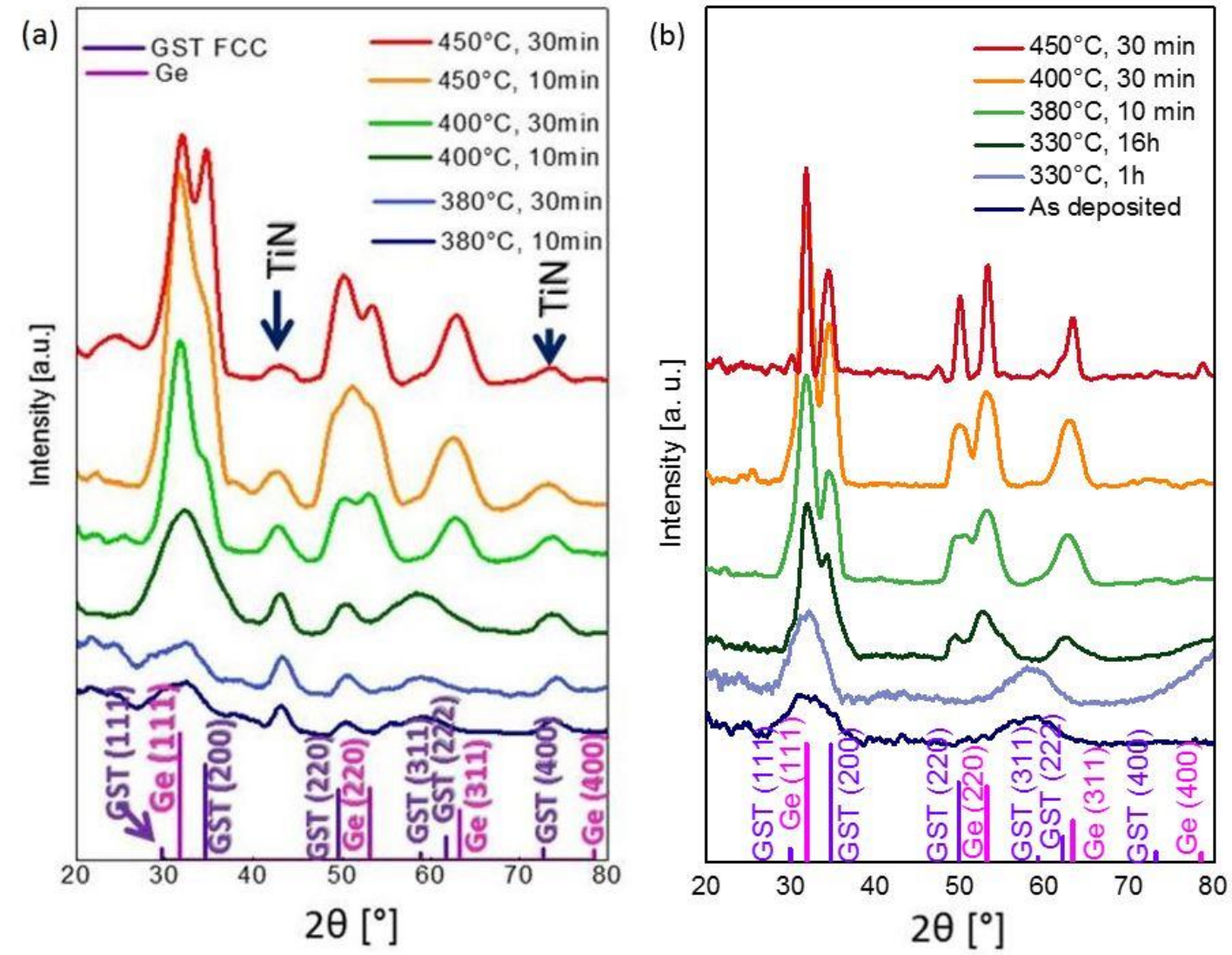
To confirm this finding we have undertaken in-situ annealing at $370^{\circ} \mathrm{C}$ in the TEM of encapsulated and non-encapsulated samples. Figure 4 shows the most striking result extracted from this study. The film left exposed to air fully crystallizes after only 5 minutes, while the film that was encapsulated stays amorphous when annealed at this temperature.
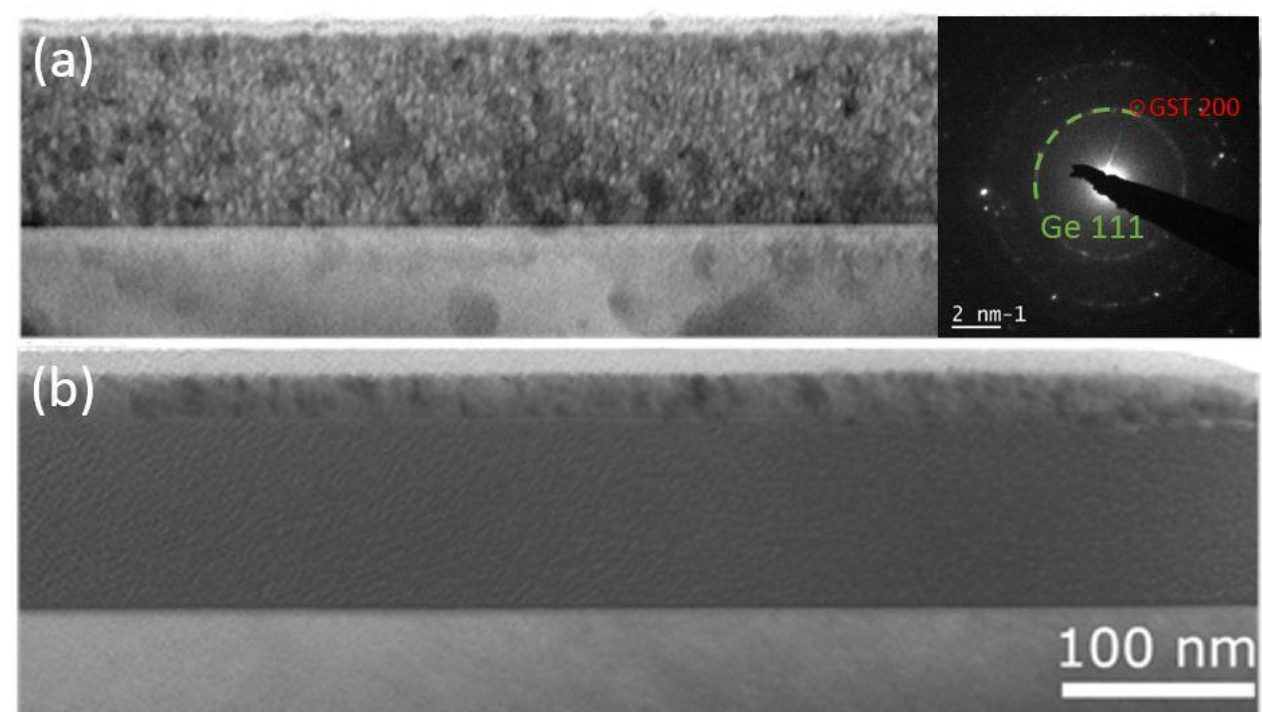

Figure 4. BF TEM images taken during in-situ annealing at $370^{\circ} \mathrm{C}$, after 5 minutes: (a) non-encapsulated and (b) encapsulated E-GST films. The electron diffraction in the inset shows that 2 crystalline phases are present in the nonencapsulated film.

In summary, while it is somehow abusive to talk about some crystallization temperature for a two-phase material, our XRD and TEM results evidence an onset of the crystallization of the Ge-rich GST layers, i.e. the temperature at which the cubic Ge phase starts to appear, is reduced by about -50 to $-70^{\circ} \mathrm{C}$, due to the exposition of the surface of the film to the atmosphere. The first goal of this work will aim at understanding why this occurs.

\subsection{Ge crystallization at the surface}


Noteworthy are the in-situ TEM results we have obtained during annealing at $330^{\circ} \mathrm{C}$, the temperature at which XRD detects the early formation of the Ge crystalline phase in the non-encapsulated samples. To carefully study the kinetics of this early crystallization, the sample temperature was increased up to $300^{\circ} \mathrm{C}$, temperature at which no structural change occurs, waiting for sample stabilization. Hence, the temperature was increased by $10^{\circ} \mathrm{C}$ every 2 minutes up to $330^{\circ} \mathrm{C}$. Figure 5 is a montage of TEM images recorded during this in-situ annealing. While after 2 minutes at $320^{\circ} \mathrm{C}$ the sample is still homogeneous and amorphous (Figure 5(a)), after setting the temperature at $330^{\circ} \mathrm{C}$ some contrasts appear in regions close to the film surface. As the annealing proceeds, these regions tend to develop, as highlighted by the red dashed line drawn in Figure 5(b), obtained after 17 minutes annealing. These contrasts have been previously shown to be due to chemical fluctuations in the film [37]. No void formation has been revealed during in-situ TEM heating, in the particular ranges of temperature and time considered here. Some small crystalline grains are also detected through their dynamical contrast (spotted, for example, by the white arrow in Figure 5(b) and (c)).
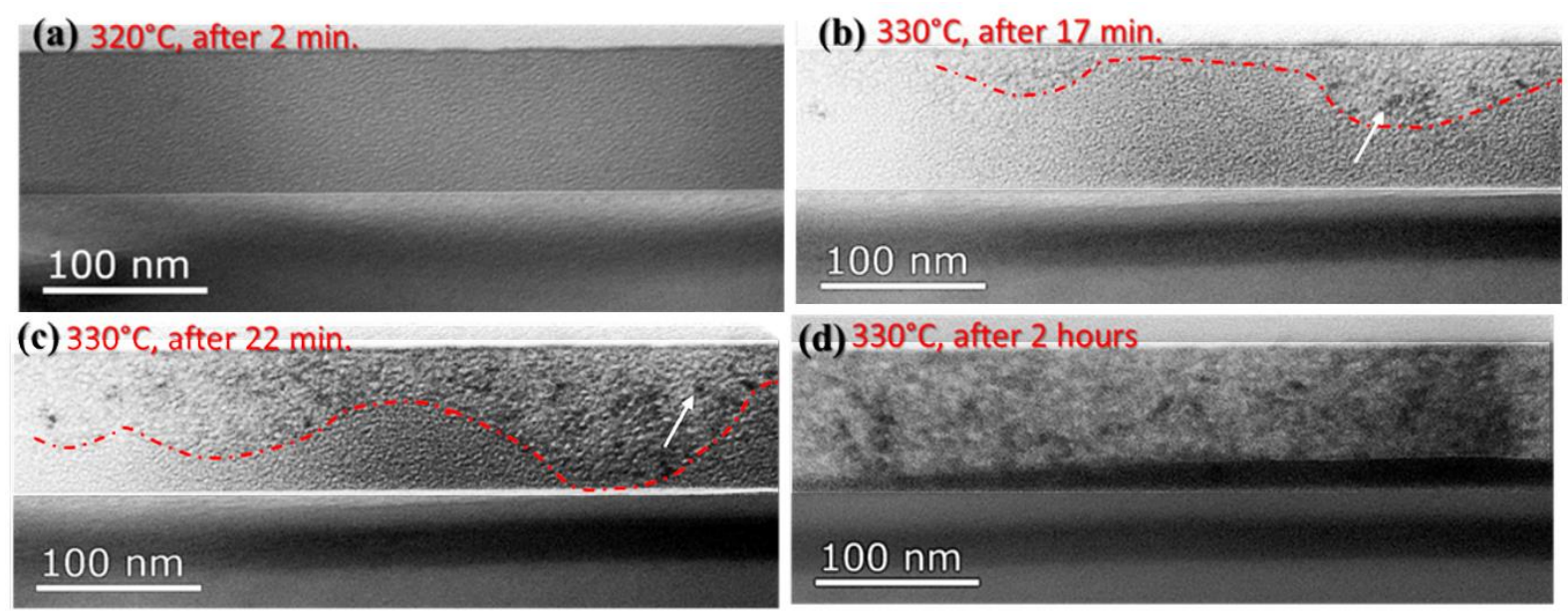

Figure 5. BF images taken during in-situ annealing in the TEM of the air-exposed film.

This sample was further analyzed ex-situ by TEM after the completion of the in-situ experiment, i.e. after 3 hours annealing at $330^{\circ} \mathrm{C}$. Figure 6(a) and 6(b) are $\mathrm{BF}$ and dark field 
(DF) images, of this sample. These images and the associated diffraction pattern demonstrate that only Ge has crystallized in the layer in the form of nanometer size grains quite evenly distributed in the film. For comparison, it is exactly the structure found in the encapsulated films after annealing for 3 hours at $380^{\circ} \mathrm{C}$ (Figure $6(\mathrm{c})$ and $6(\mathrm{~d})$ ), i.e. at a temperature $50^{\circ} \mathrm{C}$ higher than in the sample exposed to air.
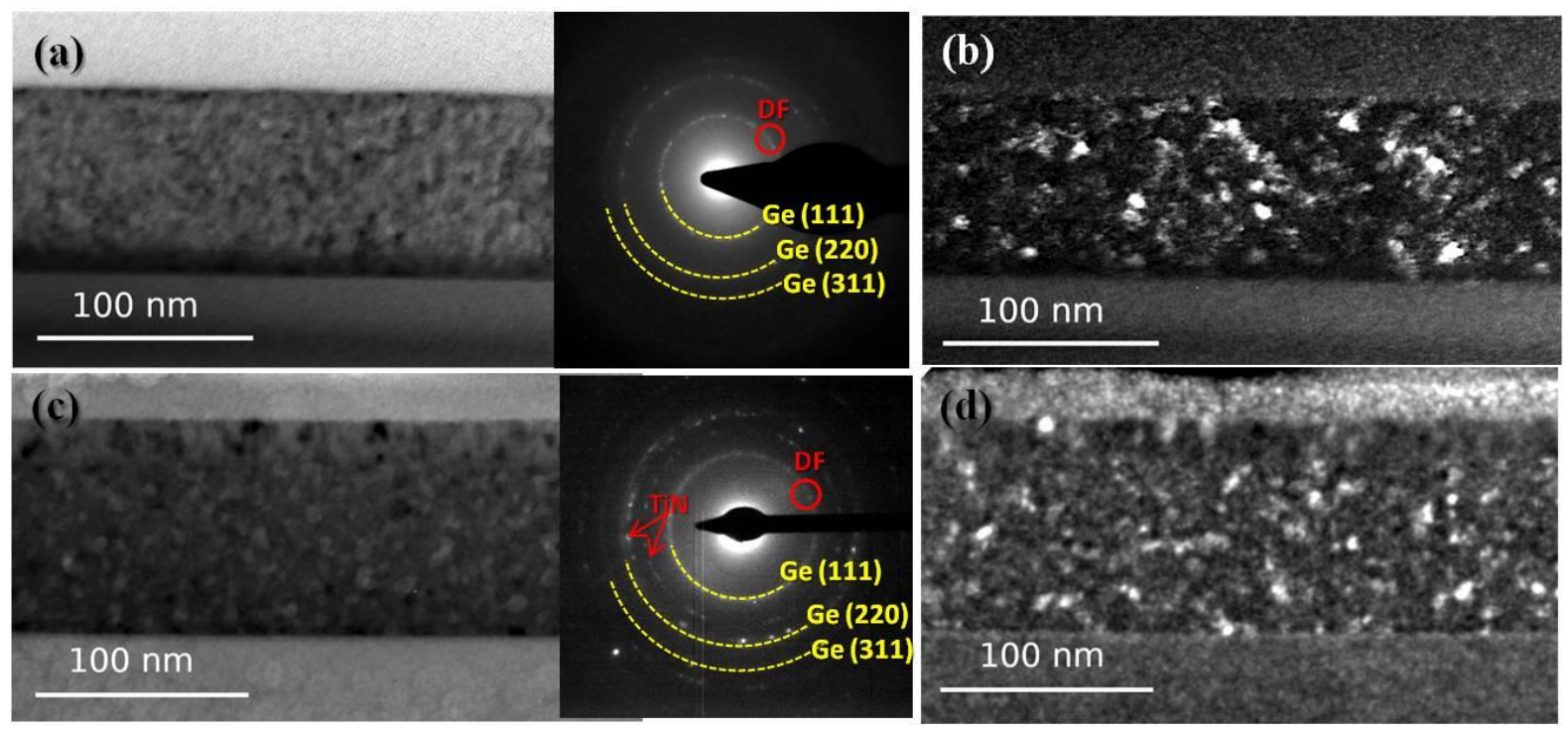

Figure 6. TEM images of the samples after in-situ annealing. Top, air-exposed film; bottom, encapsulated E-GST film. (a) and (c) are BF images while (b) and (d) are DF image using the red aperture shown in the diffraction patterns and arising from cubic Ge.

However, we evidence here a major difference between the crystallization behavior of air-exposed and encapsulated films. In encapsulated films, Ge crystallization occurs not only at a much higher temperature, but most importantly through the homogeneous nucleation of the cubic-Ge phase in the whole film [37]. In contrast, in air-exposed films, nucleation of the crystalline Ge phase occurs preferentially at the film surface and subsequently develops towards the depth. The second goal of this work will be to understand why.

To understand whether this preferential nucleation results from, or is accompanied by, a redistribution of the chemical elements within the depth of the film, we have analyzed 
its composition by STEM-EDX. Figure 7 shows the depth-distributions of the different chemical elements across the non-encapsulated film after in-situ annealing. The chemical composition of the film is found to be still homogeneous after $330^{\circ} \mathrm{C}, 3$ hours annealing and indiscernible from that of the as-deposited material. This demonstrates that the early crystallization of $\mathrm{Ge}$ at the surface of the air-exposed films does not result from the local enrichment of the layer with Ge atoms.

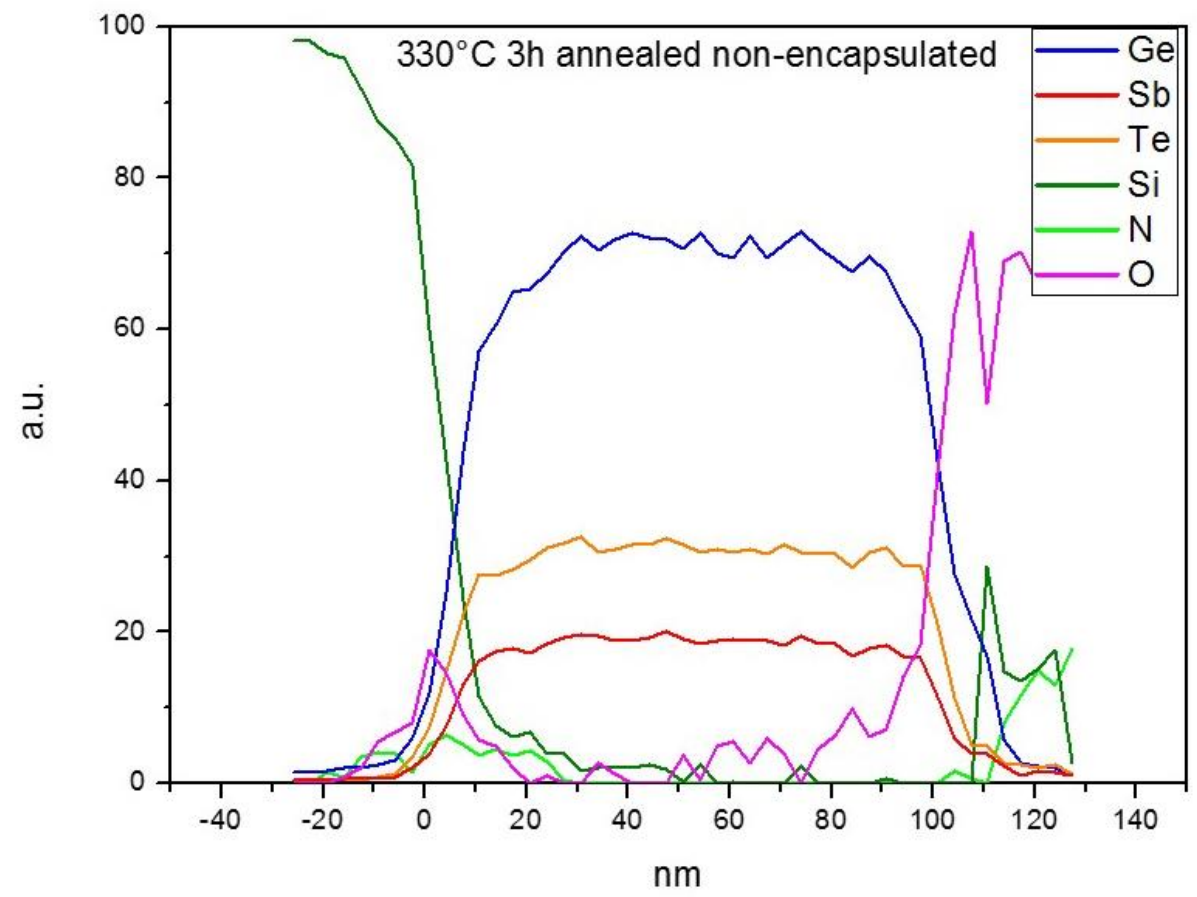

Figure 7. Depth-distributions of the different chemical elements after annealing of the air-exposed film at $330^{\circ} \mathrm{C}$ for $3 \mathrm{~h}$. Integration of STEM-EDX images along the depth.

\subsection{GST crystallization}

XRD experiments have shown that, following Ge crystallization, a GST crystalline phase starts to appear after annealing for longer times or at higher temperatures. These two phases are clearly seen in the air-exposed sample annealed at $400^{\circ} \mathrm{C}$ for 30 minutes (Figure 3(b)). Figure 8 shows the TEM structural analysis of this sample. First, the presence of the two phases is attested by the selected area diffraction pattern inserted in Figure 8(a). DF 
imaging (as shown in Figure 8(b)), using the selected spot indicated by the red circle and corresponding to the (200) plane of fcc- $\mathrm{Ge}_{2} \mathrm{Sb}_{2} \mathrm{Te}_{5}$, reveals that the film is composed of large GST grains, mostly sitting on the bottom film/substrate interface, and buried in a matrix composed of small Ge crystalline grains. However, a thin (about $20 \mathrm{~nm}$ thick) amorphous layer is detected at the surface of the film, which was not detected after less energetic annealing.
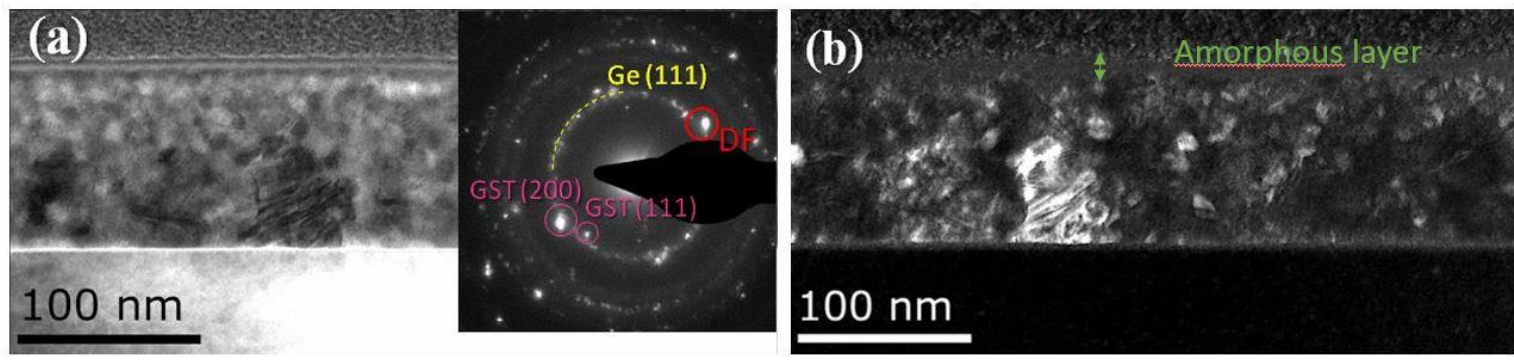

Figure 8. (a) BF TEM image of the air-exposed E-GST film annealed at $400^{\circ} \mathrm{C}$ for 30 minutes (corresponding electron diffraction in the inset). (b) DF image of the same region of the sample using the GST spot circled in red in the electron diffraction pattern.

STEM-EDX maps of the non-encapsulated E-GST annealed at $400^{\circ} \mathrm{C}$ for 30 minutes are shown in Figure 9 along with the integrated depth-profiles. These depth-profiles show the dramatic redistribution of all the chemical elements within the thickness of the film which results from this annealing. After a first analysis, three main different regions can be defined depending on their depth from the surface. From the surface and towards a depth of about 25 $\mathrm{nm}$, the material is mostly composed of a mixture of Ge and O. Then, from this depth and over the next $25 \mathrm{~nm}$, the material is almost exclusively composed of Ge, although oxygen is found penetrating this region. Finally, most of the $\mathrm{Te}$ and $\mathrm{Sb}$ atoms initially present in the whole thickness of the film are now found accumulated in the last $50 \mathrm{~nm}$, in the deepest part of the film, close to the bottom interface. 

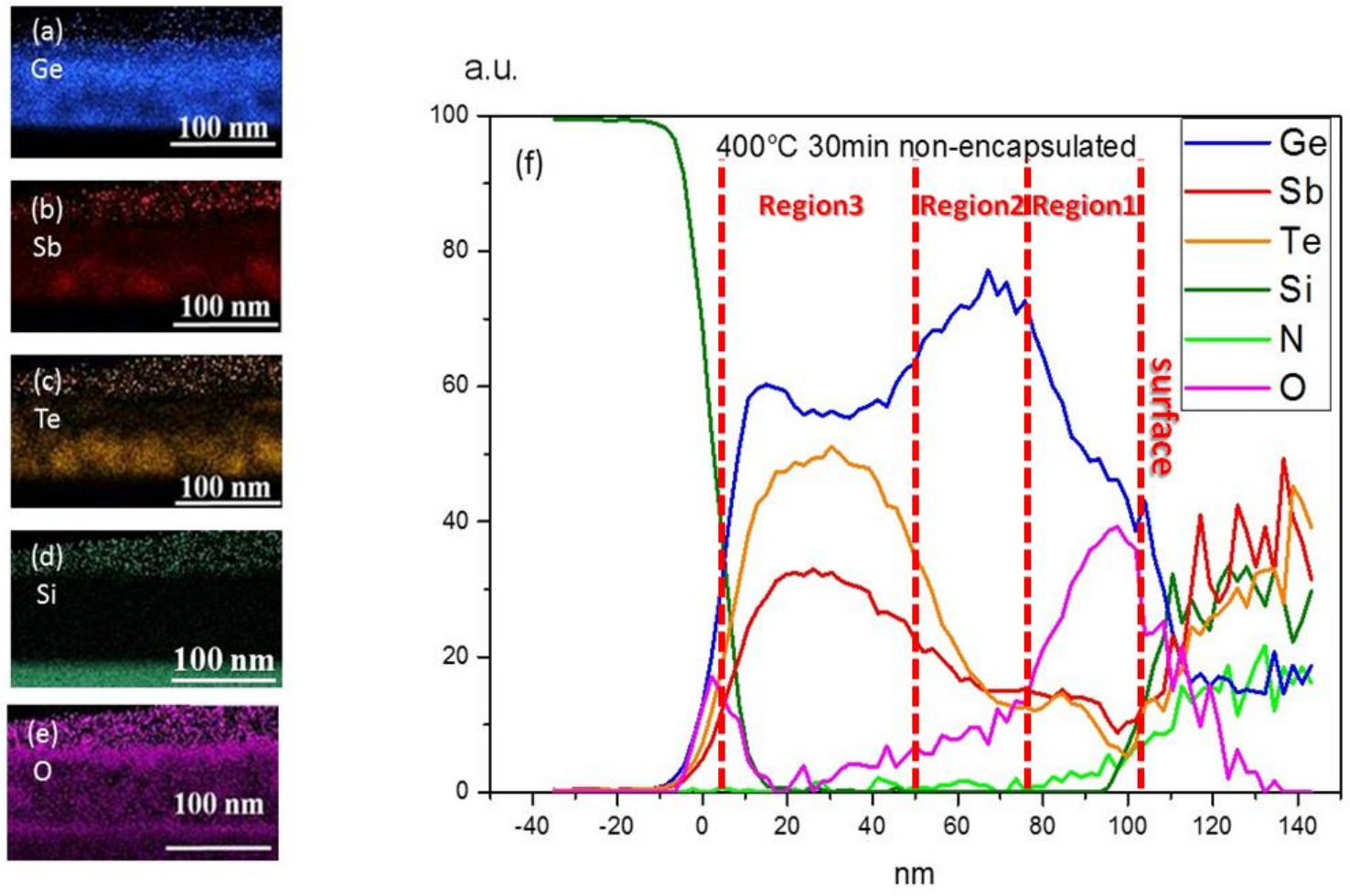

Figure 9. (a-e) STEM-EDX maps of the air-exposed E-GST sample annealed at $400^{\circ} \mathrm{C}$ for 30 minutes. (f) Depth-distributions of the different chemical elements. Integration of STEM-EDX images along the depth.

The chemical maps of the sample shown in the same Figure 9 confirm the presence of large GST grains close to the bottom interface and in regions which appear depleted in Ge. This depth localization of the GST grains is in contrast to the homogeneous dispersion of the same grains found in the encapsulated film, albeit observed after annealing at a temperature about $50^{\circ} \mathrm{C}$ higher than for air-exposed films (see Figure 10). 


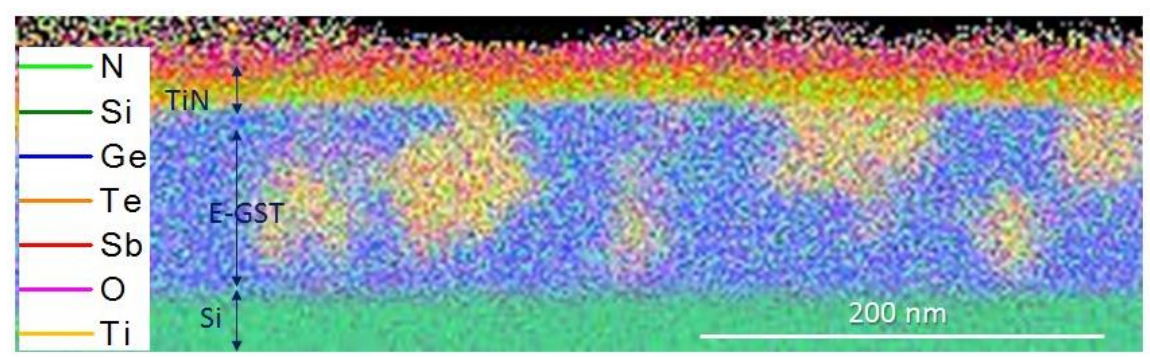

Figure 10. Composite chemical image of the TiN-encapsulated E-GST sample after annealing at $450^{\circ} \mathrm{C}$ for 30 minutes. (Superimposition of the STEM-EDX maps of the chemical elements composing the sample, namely: Ge, Sb, Te, Si, O, Ti, N).

\section{Discussion}

This experimental study has evidenced the dramatic impact of air exposure on the crystallization characteristics of amorphous Ge-rich GST alloys. Firstly, the onset of crystallization, i.e. the temperature at which $\mathrm{Ge}$ starts to crystallize, is typically $50-60^{\circ} \mathrm{C}$ lower in the films left to air exposure than in encapsulated, air protected, films. This temperature shift is found again when comparing the structure of the samples after different annealing. Secondly, while the complete crystallization of the films results in the same phase separation of the initially amorphous Ge-rich into the Ge-cubic and the fcc- $\mathrm{Ge}_{2} \mathrm{Sb}_{2} \mathrm{Te}_{5}$ phases [37], these phases are homogeneously distributed in the encapsulated film while they are spatially and in-depth distributed in the air-exposed films. In the films exposed to air, the complete re-crystallization of the film is accompanied by a strong redistribution of the chemical elements they are composed of, leading to the accumulation of Ge just below the oxide and, finally, to the preferential formation of large GST grains close to the bottom interface of the film. These different characteristics need to be discussed.

In the films left exposed to air, Ge crystallization is observed to start at a lower temperature and only from the surface of the film. The crystallization of pure Ge crystalline phase from an amorphous film of complex and non-stoichiometric composition requires two successive steps, i) phase separation and ii) crystal nucleation. The observation of a lower crystallization temperature for $\mathrm{Ge}$ is an indication that one of these two steps is facilitated in 
the air-exposed films. However, this early crystallization occurs without noticeable redistribution of Ge in the depth of the film, as evidenced by STEM-EDX (Figure 7), what somehow disqualifies an initial or faster phase separation between Ge and the other elements for being responsible of this early crystallization. It is more probable that Ge undergoes heterogeneous nucleation in this precise region, instead of the classical homogeneous nucleation observed in the encapsulated films. Interestingly, $330^{\circ} \mathrm{C}$, the temperature at which Ge crystallization is observed in the air-exposed films, is the temperature at which solid phase epitaxial regrowth of amorphous Ge on its own crystalline substrate is known to occur [38], while $380^{\circ} \mathrm{C}$ is about the temperature at which crystallization by homogeneous nucleation occurs in $\mathrm{Ge}$ [39]. Thus, it is very probable that the $50-60^{\circ} \mathrm{C}$ shift of the crystallization temperature observed between the encapsulated and air-exposed films only reflects the change of nucleation mechanism of the Ge phase from homogeneous to heterogeneous nucleation. One is now left with the task to identify the seeds, present in the oxide layer or below it, rendering possible the heterogeneous and early crystallization of Ge.

The presence of a thin oxide layer $(2-3 \mathrm{~nm})$ on the as-deposited air-exposed film and its further development up to $20 \mathrm{~nm}$ in thickness during annealing must be considered. It is known that the room temperature oxidation of $\mathrm{Ge}_{2} \mathrm{Sb}_{2} \mathrm{Te}_{5}$ leads to the formation of both $\mathrm{SbO}_{\mathrm{x}}$ and $\mathrm{GeO}_{\mathrm{x}}$ at the surface and to the repelling of the Te atoms below it $[11,29,30,40]$. Moreover, crystalline $\mathrm{Sb}_{2} \mathrm{O}_{3}$ is known to form upon the reaction of $\mathrm{Sb}$ with $\mathrm{O}$ at temperatures in the $270-360^{\circ} \mathrm{C}$ range $[41,42]$. It is thus probable that such crystalline seeds form at the surface of the air-exposed films during annealing at temperatures of the order of $300^{\circ} \mathrm{C}$, i.e. slightly below the one required for Ge to crystallize. In other words, annealing of an oxidized film would lead to the fabrication of crystalline $\mathrm{Sb}_{2} \mathrm{O}_{3}$ seeds allowing the subsequent heterogeneous crystallization of $\mathrm{Ge}$ at $330^{\circ} \mathrm{C}$ to take place. However, the possibility that the oxygen atoms themselves or $\mathrm{Ge}-\mathrm{O}$ complexes directly act as seeds for crystallization cannot 
be ruled out [40]. Anyhow, our experimental results demonstrate that the oxidized surface layer of the film does contain, in the as-deposited state, the chemical element(s) which will form the nuclei able to support Ge heterogeneous nucleation and crystallization during annealing at $330^{\circ} \mathrm{C}$.

Once Ge crystallization has started, the same thermodynamics that drives the two-step crystallization of air-protected Ge-rich alloys operates [37]. Chemical gradients between the Ge-rich amorphous matrix and the Ge grains progressively drive the excess Ge out of the matrix, favoring the growth of the Ge grains, until its concentration in the remaining matrix is low enough to allow the GST phase to crystallize. In the encapsulated films, the Ge grains are homogeneous distributed along the depth of the films and thus these gradients are randomly oriented. In average, they do not generate any redistribution of the chemical elements along the depth of the films. In contrast, in surface oxidized films, the first Ge grains are preferably located close to the surface of the films and thus these gradients are oriented from the depth towards the surface of the film. This is why the complete crystallization of the films is accompanied by a massive transfer of Ge from the bulk towards the surface and a disruption of the initial stoichiometry of the film. This Ge transfer is visibly compensated by $\mathrm{Te}$ and $\mathrm{Sb}$ transfer in the opposite direction.

Our hypothesis can be further tested through the attentive observation of the redistribution of the different elements obtained after complete recrystallization of the films at $400^{\circ} \mathrm{C}$ for 30 minutes, shown in Figure 9. Indeed, this figure and the associated chemical maps not only show the accumulation of Ge below the oxidized surface but also close to the substrate/film interface. This characteristic is certainly to be correlated to the presence of a thin silicon oxide layer between the Si wafer and the E-GST film after deposition. While not evidenced during in-situ annealing in the TEM, Ge grains have probably nucleated early and preferentially also in this region and have also contributed to drive Ge out of the matrix and 
towards this interface. Whether it is the formation of germanium or antimony oxides resulting from the oxidation of the GST layer in contact with the $\mathrm{SiO}_{2}$ layer and at the surface or it is the sole presence of $\mathrm{O}$ atoms in these regions which promotes the heterogeneous nucleation of Ge grains cannot be formally answered by this work. However, we provide the important information that, as part of some germanium or antimony oxides or as an isolated impurity, oxygen does favor the heterogeneous nucleation of the crystalline phase of Ge during annealing.

Finally, our results confirm previous reports about the dramatic effect of air exposure, i.e. surface oxidation, on the crystallization characteristics of GST alloys. For stoichiometric $\mathrm{Ge}_{2} \mathrm{Sb}_{2} \mathrm{Te}_{5}$ and GeTe materials, the selective oxidation of $\mathrm{Ge}$ and $\mathrm{Sb}$ atoms at the surface at room temperature results in some local imbalance of the initial stoichiometry below the oxide and Te accumulation. In GeTe, Te crystallizes in this region during annealing at a much lower temperature than GeTe and provides the seeds allowing the further heterogeneous crystallization of the remaining GeTe alloy [11] below this layer. $\mathrm{In}_{\mathrm{Ge}_{2}} \mathrm{Sb}_{2} \mathrm{Te}_{5}$ alloys, the selective consumption of $\mathrm{Ge}$ and $\mathrm{Sb}$ atoms due to oxidation and the stoichiometric imbalance which results not only promote the crystallization of the Te phase at low temperature but also to the partial crystallization of the GST alloy into the less rich $\mathrm{Ge}_{1} \mathrm{Sb}_{2} \mathrm{Te}_{4}$ phase $[32,40]$. In Ge-rich GST alloys, while the effect of oxidation also results in a dramatic lowering of T $\chi$, it is not the early crystallization of $\mathrm{Te}$ which initiates the overall crystallization process. Probably, the films are Ge-rich enough when deposited so that, even after oxidation, regions of pure Te are not formed below the surface and that the local Ge concentration in the region is still that of a Ge-rich GST layer. Instead, seeds form, probably from $\mathrm{Sb}_{2} \mathrm{O}_{3}$, and allow the heterogeneous crystallization of $\mathrm{Ge}$ to start at $330^{\circ} \mathrm{C}$, triggering later that of the $\mathrm{Ge}_{2} \mathrm{Sb}_{2} \mathrm{Te}_{5}$ material at a slightly larger temperature. 


\section{Conclusion}

We have studied the effect of air exposure on the crystallization behavior of amorphous Ge-rich GST films. For this, we have compared the structural and chemical characteristics of films left several months exposed to air at room temperature with those shown by TiN-encapsulated, i.e. air-protected films. As observed in many GST alloys, the effect of air exposure is to significantly lower the "crystallization temperature", actually the temperature at which the onset of crystallization starts, by $50-60^{\circ} \mathrm{C}$. Moreover, instead of the homogeneous nucleation observed in encapsulated films, crystallization proceeds from the surface towards the bulk of the film and results in a massive redistribution of the chemical elements within the film, observed after complete recrystallization of the films. As in encapsulated films, crystallization starts with the formation of Ge grains, which further grow by dragging the Ge excess out of the matrix until its concentration is low enough to allow the GST phase to nucleate. However, in the air-exposed films, this Ge crystallization preferentially occurs at the film surface, where an oxide layer is rapidly formed at room temperature and further develops during annealing. The temperature shift of $50-60^{\circ} \mathrm{C}$ which is observed, from $330^{\circ} \mathrm{C}$ for the air-exposed films to $380^{\circ} \mathrm{C}$ for the encapsulated films, does correspond to the temperature shift reported between heterogeneous and homogeneous crystallizations of amorphous Ge. These observations, along with the detection of some Ge accumulation also in the vicinity of the $\mathrm{SiO}_{2} / \mathrm{E}-\mathrm{GST}$ bottom interface, tend to demonstrate that the seeds that promote this heterogeneous nucleation of the Ge cubic phase involve oxygen, directly as an impurity atom or complex, or most probably through a crystalline $\mathrm{Sb}_{2} \mathrm{O}_{3}$ phase. Since all these effects are due to surface oxidation, we expect the same general behavior in non-encapsulated films as well as in films encapsulated in reactive oxygen environment. 


\section{Acknowledgements}

The authors would like to thank the people in charge of TEM and FIB facilities at CEMES, in particular S. Joulie and R. Cours for their precious technical support. We thank also Dr. Antonio Mio for his suggestions. This work has been partially funded by Minefi through the Nano2017 initiative and by the grant Labex NEXT no. ANR-10-LABX-0037 in the framework of the "Programme des Investissements d'Avenir".

\section{References}

[1] M. Wuttig and N. Yamada: Phase-change materials for rewriteable data storage. Nat. Mater. 6, 824 (2007).

[2] W. Wełnic and M. Wuttig: Reversible switching in phase-change materials. Materials today 11, 20 (2008).

[3] B. C. Lee, P. Zhou, J. Yang, Y. Zhang, B. Zhao, E. Ipek, O. Mutlu, D. Burger: PhaseChange Technology and the Future of Main Memory. IEEE Micro 30, 131 (2010).

[4] G.W. Burr, M. J. Breitwisch, M. Franceschini, D. Garetto, K. Gopalakrishnan, B. Jackson, B. Kurdi, C. Lam, L. A. Lastras, A. Padilla, B. Rajendran, S. Raoux and R. S. Shenoy: Phase change memory technology. J. Vac. Sci. Technol. B 28, 223-262 (2010).

[5] W. Zhang, R. Mazzarello, M. Wuttig, E. Ma: Designing crystallization in phase- change materials for universal memory and neuro- inspired computing. Nat. Rev. Mater. 4, 150-168 (2019).

[6] A. Lotnyk, M. Behrens, B. Rauschenbach: Phase change thin films for non-volatile memory applications. Nanoscale Adv. 1, 3836-3857 (2019).

[7] X.-B. Li, N.-K. Chen, X.-P. Wang, H.-B. Sun: Phase-Change Superlattice Materials toward Low Power Consumption and High Density Data Storage: Microscopic Picture, Working Principles, and Optimization. Adv. Funct. Mater. 28, 1803380 (2018).

[8] P. Noé, C. Vallée, F. Hippert, F. Fillot, J.-Y. Raty: Phase-change materials for nonvolatile memory devices: from technological challenges to materials science issues. Semicond. Sci. Technol. 33, 013002 (2018).

[9] G. Bruns, P. Merkelbach, C. Schlockermann, M. Salinga, M. Wuttig, T. D. Happ, J. B. Philipp, M. Kund: Nanosecond switching in GeTe phase change memory cells. Appl. Phys. Lett. 95, 043108 (2009).

[10] D. Loke, T. H. Lee, W. J. Wang, L. P. Shi1, R. Zhao, Y. C. Yeo, T. C. Chong, S. R. Elliott: Breaking the Speed Limits of Phase-Change Memory. Science 336, 1566 (2012). 
[11] P. Noé, C. Sabbione, N. Bernier, N. Castellani, F. Fillot, F. Hippert: Impact of interfaces on scenario of crystallization of phase change materials. Acta Mater. 110, 142 (2016).

[12] R. Berthier, N. Bernier, D. Cooper, C. Sabbione, F. Hippert, P. Noé: In situ observation of the impact of surface oxidation on the crystallization mechanism of GeTe phase-change thin films by scanning transmission electron microscopy. J. Appl. Phys. 122, 115304 (2017).

[13] I. S. Kim, S.L. Cho, D.H. Im, E.H. Cho, D.H. Kim, G.H. Oh, D.H. Ahn, S.O. Park, S.W. Nam, J.T. Moon and C.H. Chung: High performance PRAM cell scalable to sub-20nm technology with below 4F2 cell size, extendable to DRAM applications. 2010 Symposium on VLSI Technology, Honolulu, 203 (2010).

[14] V. Sousa and G. Navarro: Material engineering for PCM devices optimization in Phase Change Memory-Device physics, Reliability and Applications (Cham: Springer) chapter 7 (2017).

[15] M. Aoukar: Dépôt de matériaux à changement de phase par PE-MOCVD à injection liquide pulsée pour des applications mémoires PCRAM (PhD Thesis, University of Grenoble Alpes, 2015).

[16] M. Coué: Electrical characterization \& TEM analyses of the physical mechanisms governing reliability of Ge-rich Phase-Change Memories ( $\mathrm{PhD}$ Thesis, University of Grenoble Alpes, 2016).

[17] A. Kiouseloglou: Caractérisation et conception d'architectures basées sur des mémoires à changement de phase, (PhD Thesis, University of Grenoble Alpes, 2015).

[18] P. Zuliani, E. Varesi, E. Palumbo, M. Borghi, I. Tortorelli, D. Erbetta, G. Dalla Libera, N. Pessina, A. Gandolfo, C. Prelini, L. Ravazzi, R. Annunziata: Overcoming Temperature Limitations in Phase Change Memories With Optimized $G e_{x} S b_{y} T e_{z}$. IEEE Trans. Electron Devices 60, 4020 (2013).

[19] K. H. Kim, J. G. Chung, Y. K. Kyoung, J. C. Park and S. J. Choi: Phase-change characteristics of nitrogen-doped $\mathrm{Ge}_{2} \mathrm{Sb}_{2} \mathrm{Te}_{5}$ films during annealing process. J. Mater. Sci.: Mater. Electron. 22, 52-55 (2011).

[20] G. Navarro, V. Sousa, P. Noe, N. Castellani, M. Coue, J. Kluge, A. Kiouseloglou, C. Sabbione, A. Persico, A. Roule, O. Cueto, S. Blonkowski, F. Fillot, N. Bernier, R. Annunziata, M. Borghi, E. Palumbo, P. Zuliani and L. Perniola: $\mathrm{N}$-doping impact in optimized Ge-rich materials based phase-change memory. 2016 IEEE 8th International Memory Workshop (IMW), Paris, 1 (2016).

[21] X. Zhou, M. Xia, F. Rao, L. Wu, X. Li, Z. Song, S. Feng and H. Sun: Understanding Phase-Change Behaviors of Carbon-Doped $\mathrm{Ge}_{2} \mathrm{Sb}_{2} \mathrm{Te}_{5}$ for Phase-Change Memory Application. ACS Appl. Mater. Interfaces 6, 14207 (2014).

[22] T. H. Jeong, H. Seo, K. L. Lee, S. M. Choi, S. J. Kim and S. Y. Kim: Study of oxygendoped GeSbTe film and its effect as an interface layer on the recording properties in the blue wavelength. Jpn J. Appl. Phys. 40, 1609 (2001). 
[23] P. Lazarenko, H. P. Nguyena, S. Kozyukhina and A. Sherchenkov: Influence of Bi doping on electrical and optical properties of phase change material $\mathrm{Ge}_{2} \mathrm{Sb}_{2} \mathrm{Te}_{5}$. J. Optoelectron. Adv. Mater. 13, 1400 (2011).

[24] K-J Choi, S-M Yoon, N-Y Lee, S-Y Lee, Y-S Park, B-G Yu and S-O Ryu: The effect of antimony-doping on $\mathrm{Ge}_{2} \mathrm{Sb}_{2} \mathrm{Te}_{5}$, a phase change material. Thin Solid Films 516, 8810 (2008).

[25] G. Navarro, M. Coué, A. Kiouseloglou, P. Noé, F. Fillot, V. Delaye, A. Persico, A. Roule, M. Bernard, C. Sabbione, D. Blachier, V. Sousa, L. Perniola, S. Maitrejean, A. Cabrini, G. Torelli, P. Zuliani, R. Annunziata, E. Palumbo, M. Borghi, G. Reimbold, B. De Salvo: Trade-off Between SET and Data Retention Performance Thanks to Innovative Materials for Phase-Change Memory. 2013 IEEE International Electron Devices Meeting, Washington, DC, 21.5.1 (2013).

[26] F. Arnaud, P. Zuliani, J. P. Reynard, A. Gandolfo, F. Disegni, P. Mattavelli, E. Gomiero, G. Samanni, C. Jahan, R. Berthelon, O. Weber, E. Richard, V. Barral, A. Villaret, S. Kohler, J. C. Grenier, R. Ranica, C. Galloni, A. Souhaite, D. Ristoiu, L. Favennec, V. Caubet, S. Delmedico, N. Cherault, R. Beneyton, S. Chouteau, P. O. Sassoulas, A. Vernhet, Y. Le Friec, F. Domengie, L. Scotti, D. Pacelli, J. L. Ogier, F. Boucard, S. Lagrasta, D. Benoit, L. Clement, P. Boivin, P. Ferreira, R. Annunziata, P. Cappelletti: Truly Innovative 28nm FDSOI Technology for Automotive Micro-Controller Applications embedding 16MB Phase Change Memory. 2018 IEEE International Electron Devices Meeting (IEDM), San Francisco, CA, 18.4.1 (2018).

[27] A. L. Serra, O. Cueto, N. Castellani, J. Sandrini, G. Bourgeois, N. Bernier, M. C. Cyrille, J. Garrione, M. Bernard, V. Beugin, A. André, J. Guerrero, G. Navarro, E. Nowak: Outstanding Improvement in 4Kb Phase-Change Memory of Programming and Retention Performances by Enhanced Thermal Confinement. 2019 IEEE 11th International Memory Workshop (IMW), Monterey, CA, USA, 1 (2019).

[28] B. J. Kooi, W. M. G. Groot, J. Th. M. De Hosson: In situ transmission electron microscopy study of the crystallization of $\mathrm{Ge}_{2} \mathrm{Sb}_{2} \mathrm{Te}_{5}$. J. Appl. Phys. 95, 924 (2004).

[29] E. Gourvest, B. Pelissier, C. Vallee, A. Roule, S. Lhostis, S. Maitrejean, Impact of Oxidation on $\mathrm{Ge}_{2} \mathrm{Sb}_{2} \mathrm{Te}_{5}$ and GeTe Phase-Change Properties. J. Electrochem. Soc. 159, H373 (2012).

[30] R. Golovchak, Y. G. Choi, S. Kozyukhin, Yu. Chigirinsky, A. Kovalskiy, P. XiongSkiba, J. Trimble, R. Pafchek, H. Jain: Oxygen incorporation into GST phase-change memory matrix. Appl. Surf. Sci. 332, 533 (2015).

[31] A. N. D. Kolb, N. Bernier, E. Robin, A. Benayad, J.-L. Rouvière, C. Sabbione, F. Hippert, P. Noé: Understanding the Crystallization Behavior of Surface-Oxidized GeTe Thin Films for Phase-Change Memory Application. ACS Appl. Electron. Mater. 1, 701 (2019).

[32] Y. Kim, S. A. Park, J. H. Baeck, M. K. Noh, K. Jeong: Phase separation of a $\mathrm{Ge}_{2} \mathrm{Sb}_{2} \mathrm{Te}_{5}$ alloy in the transition from an amorphous structure to crystalline structures. J. Vac. Sci. Technol. A 24, 929 (2006). 
[33] X. Wei, L. Shi, T. C. Chong, R. Zhao, L. H. Koon: Thickness dependent nanocrystallization in Ge2Sb2Te5 films and its effect on devices. Jpn. J. Appl. Phys. 46, 2211 (2007).

[34] S. Raoux, J. L. Jordan-Sweet, A. J. Kellock: Crystallization properties of ultrathin phase change films. J. Appl. Phys. 103114310 (2008).

[35] R. E. Simpson, M. Krbal, P. Fons, A. V. Kolobov, J. Tominaga, T. Uruga, H. Tanida: Toward the Ultimate Limit of Phase Change in $\mathrm{Ge}_{2} \mathrm{Sb}_{2} \mathrm{Te}_{5}$. Nano Lett. 10, 414419 (2010).

[36] M. Agati, F. Renaud, D. Benoit, A. Claverie: In-situ transmission electron microscopy studies of the crystallization of $\mathrm{N}$-doped Ge-rich GeSbTe materials. MRS Comm. 8, 1145 (2018).

[37] M. Agati, M. Vallet, S. Joulié, D. Benoit, A. Claverie: Chemical phase segregation during the crystallization of Ge-rich GeSbTe alloys. J. Mater. Chem. C 7, 8720 (2019).

[38] A. Claverie, S. Koffel, N.Cherkashin, G. Benassayag, P.Scheiblin: Amorphization, recrystallization and end of range defects in germanium. Thin Solid Films 518, 2307 (2010).

[39] A. Heya, K. Kanda, K. Toko, T. Sadoh, S. Amano, N. Matsuo, S. Miyamoto, M. Miyao, T. Mochizuki: Low-temperature crystallization of amorphous silicon and amorphous germanium bysoft X-ray irradiation. Thin Solid Films 534, 334 (2013).

[40] E. Morales-Sánchez, J. González-Hernández, P. Herrera-Fierro, B. Chao, Yu. Kovalenko, E. Prokhorov: Influence of oxygen on the crystallization process in Ge:Sb:Te:O films. 2006 3rd International Conference on Electrical and Electronics Engineering, Veracruz, 1 (2006).

[41] A. J. Rosenberg, A. A. Menna, T. P. Turnbull: Kinetics of the Oxidation of Antimony. J. Electrochem. Soc. 107, 196 (1960).

[42] C. H. Xu, S. Q. Shi, Q. Tang: Synthesis of Antimony Oxide Nanoparticles by Thermal Oxidation. Technical Proceedings of the 2005 NSTI Nanotechnology Conference and Trade Show 2, 54 (2005). 